See discussions, stats, and author profiles for this publication at: https://www.researchgate.net/publication/338146140

The role of task classification and design in curriculum making for preservice teachers of mathematics: The role of task for preservice teachers of mathematics

Article in Curriculum Journal · December 2019

DOI: 10.1002/curj.18

2 authors, including:

Majella Dempsey

Maynooth University

27 PUBLICATIONS 97 CITATIONS

SEE PROFILE

Some of the authors of this publication are also working on these related projects:

Poject Positive Education View project

Project Task Evaluation and Development View project 


\title{
The role of task classification and design in curriculum making for preservice teachers of mathematics
}

\author{
Majella Dempsey, ${ }^{\star}(\mathbb{D})$ and Ann O’Shea \\ Maynooth University, Ireland
}

This paper reports on a research project undertaken with a group $(n=19)$ of Irish preservice student teachers (PSTs) during the third year of a five-year undergraduate education course. A series of workshops were carried out on the classification and design of mathematics tasks. The research is presented as a case study using mixed methods to gather data at three points, before the workshops, after the workshops, and two years later, when PSTs were in their final year. We argue that task classification and design are curriculum-making activities for mathematics teachers. Through critically classifying and designing mathematics tasks, PSTs developed skills of evaluating the cognitive demand of tasks and showed evidence of using these skills in curriculum making. Through using frameworks to classify tasks, the PSTs demonstrated a capacity to take a more critical role in curriculum making. Our data show that the development of skills in these areas has lasting effects on PSTs' practices and willingness to engage meaningfully with the curriculum in mathematics. The research highlights the need for PSTs to work on evaluating and designing tasks. How frameworks can support and enhance PSTs' capacity to make curricular decisions is evidenced.

Keywords: curriculum; frameworks; mathematics; tasks

\section{Introduction}

This paper reports on a research project undertaken with a group $(n=19)$ of Irish preservice student teachers (PSTs) during the third year of a five-year teacher education course. A series of workshops were carried out on the critical classification and design of mathematics tasks. Data were gathered at three stages of the research, prior to the workshops, immediately after the workshops, and two years later. For the purpose of this research, a 'mathematical task' is a problem or set of problems that address a specific mathematical idea; they are situated between teaching, learning and assessment (Smith \& Stein, 1998). The types of tasks that students engage with have been shown to influence their development of mathematical skills (Jonsson et al., 2014), and, studies have shown that students spend the majority of their time in mathematics classes working on tasks (Haggarty \& Pepin, 2002; Boston \& Smith, 2009). Smith and Stein (1998) assert that the highest learning gains in mathematics are related to how tasks are set up and implemented to ensure students are engaged

${ }^{\star}$ Corresponding author. Department of Education, Maynooth University, Maynooth, Ireland. Email: majella.dempsey@mu.ie 
in high levels of cognitive thinking and reasoning (see also Swan, 2011; Boston, 2013). Many challenging questions arise from this assertion for preservice mathematics teachers, such as: what is a good learning task? How is a good learning task developed? How is it implemented in a mathematics classroom? These questions are especially relevant in Ireland, given that a report on mathematics education found that traditional approaches to teaching and learning were widespread and recommended that students engage with more tasks that require higher order thinking skills such as problem-solving and justification (Jeffes et al., 2013). This requires what Wallace and Priestley described as 'a new epistemology of pedagogy' for mathematics teachers $(2017$, p. 1). This research is concerned with how PSTs on an undergraduate course, work on, and with different mathematical tasks, and what influence this has on their practice and tendency to act as curriculum makers.

In this introductory section, we present the research questions, review the literature on task development, and introduce the two task frameworks used in this research. The first framework is that of Smith and Stein (1998), which classifies the level of cognitive demand (LCD) of tasks. In order to help the PSTs to move from evaluating tasks to designing them, we used Swan's framework for task design (2008). This describes five task types that encourage concept development and provides very clear design principles to inform task development and implementation. Our conceptual framework uses the concept of curriculum development and making (Shawer, 2010; Wallace \& Priestley, 2017; Priestley \& Philippou, 2018).

This paper addresses the following research questions:

1. In what ways did preservice teachers' ability to classify the cognitive demands of mathematical tasks develop during their participation in a module on critical classification and design of mathematical tasks?

2. In what ways did preservice teachers' ability to design or adapt mathematical tasks develop during their participation in a module on critical classification and design of mathematical tasks?

3. How did the development of these abilities impact on how PSTs used tasks in curriculum development and making?

We provide an overview of the frameworks used as part of the research project and the methodology used to collect data. We present the key findings from the research and discuss the salient themes emerging as they pertain to preservice teacher education. Finally, we summarise our recommendations and conclusions.

\section{Literature review}

\section{Context for the research - mathematics education in Ireland}

In Ireland, lower and upper secondary education mathematics underwent curriculum reform in 2008 with the introduction of Project Maths. ${ }^{1}$ Project Maths aimed to move away from rote learning aspects of the previous courses in order to 'foster positive attitudes towards mathematics in students' through contextual problems and applications' (NCCA, 2008, p. 6). A key aspect of this course is that of problem solving 
and the curriculum specifications make multiple explicit references to problem solving in relation to mathematical reasoning. 'A task must engage learners and present them with a challenge that requires exploration. Problem-solving tasks activate creative mathematical thinking processes as opposed to imitative thinking processes activated by routine tasks' (NCCA, 2008, p. 11). PSTs need to enact, translate and mediate this written curriculum policy in different contexts (Priestley \& Philippou, 2018). Lithner (2017) contends that 'one of the most persistent challenges in mathematics education is replacing the dominant task and teaching designs, which are based on imitation of given solution methods' (p. 937). This over-reliance on algorithmic learning is counterproductive to developing mathematical skills (Jonsson et al., 2014). Mathematics education in Ireland continues to be characterised by this style of teaching where the backwash effect of a high stakes examination is reported to have led to drill and practice of algometric procedures and learning of facts (Conway \& Sloane, 2005; Jeffes et al., 2013; Banks \& Smyth, 2015).

The dependence of mathematics teachers on textbooks in their teaching appears to be a phenomenon in many countries (Haggarty \& Pepin, 2002; Jeffes et al., 2013). Haggarty and Pepin (2002) report on the dominance of the textbook in the mathematics classroom and conclude that without time to prepare for teaching, and, we would add, the competences to enrich the curriculum materials available, textbooks take on a prominence in 'relation to teacher thinking and planning' (p. 588, see also Jones \& Pepin, 2016). Teachers' over-reliance on the textbook can also encourage algorithmic thinking and when students are exposed repeatedly to this level of task they may become unable to solve unfamiliar problems (Bergqvist \& Lithner, 2012). In this way, the choice of task used in teaching not only influences what is learned but also whether the learner perceives the subject of mathematics as either a list of steps to be learned off or as a subject requiring reasoning, creative thinking and cognitive demand (Stein et al., 1996).

This is of concern as a review of mathematics books in Ireland found that all available books fell short of the standard needed to support mathematics teaching at that time and furthermore, they especially fell short on the integration of technology, approaches to teaching for understanding and problem solving (O'Keeffe \& O'Donoghue, 2011). Algorithms are useful if the object is only to solve a task in a quick and efficient way. However, if the purpose is to develop mathematical competences such as the ability to understand, reason, and do mathematics there is a need to move beyond applying algorithms to tasks that require some level of creative reasoning and high levels of cognitive demand (Thanheiser, 2014; Lithner, 2017). It is in this complex space where the teacher choses, modifies and sometimes designs tasks that the link to the teacher as curriculum maker is most evident (Remillard, 2005; Jones \& Pepin, 2016).

\section{Curriculum making}

PSTs working with schools in reform-oriented mathematical contexts are presented with a number of dilemmas (Conway et al., 2013). These are the mismatch between their experience as a secondary school student studying mathematics, their 
experience as a university student studying mathematics and education, and their experience as a preservice teacher on placement in a school. The impact of these three types of experience on how PSTs construct, deconstruct and reconstruct their professional identities is well documented (see for example Flores \& Day, 2006). Part of this development of professional identity is how PSTs approach curriculum, with what Olson refers to as 'unique narratives of experience' (2000, p. 173). Teacher education can underplay and misrepresent the process of curriculum making and the complexity of teaching as a social process (Priestley \& Philippou, 2018).

In this paper, we will use Remillard and Heck's definition of the mathematics curriculum, that is 'a plan for the experiences that learners will encounter, as well as the actual experiences they do encounter, that are designed to help them reach specified mathematics objectives' (Remillard \& Heck, 2014, p. 707). This definition focuses on experiences rather than lists of topics or objectives, and thus emphasises the role of the teacher and the teaching resources they use. Remillard and Heck (2014) distinguish between the official and the operational curriculum and further divide the operational into three parts: teacher-intended curriculum, enacted curriculum and student outcomes. The teacher-intended curriculum refers to the plans and decisions that teachers make prior to instruction, while the enacted curriculum emerges from the classroom experience of both students and teachers including their inthe-moment interactions. Since we know that much of the time in mathematics classes is devoted to working on tasks, we see that tasks have a large role to play in both the planning for each lesson (teacher-intended curriculum) and the classroom experience (enacted curriculum). Research has shown (see for example Sears \& Chávez, 2014) that the resources that teachers use (including textbooks and tasks) effect the enacted curriculum in ways such as signalling what is valued and providing different types of learning opportunities. The importance of tasks is also evident in Remillard's (1999, 2005) model of curriculum development. She considers three aspects of the work of teachers as they use a textbook: the design arena, where teachers select or design tasks and activities; the construction arena, where teachers use and adapt tasks in the classroom and respond to student needs; the mapping arena, where teachers make choices about organisation and sequencing of topics. Thus, it is important to study how teachers use and develop the curriculum.

Shawer (2010), building on the work of Synder et al. (1992) identifies three curriculum strategies. Curriculum-transmission strategies are where the textbook and teacher's guide are the single source of pedagogical instructions and the teachers follow them page-by-page and task-by-task. He describes curriculum-making strategies as to where the teacher develops their own materials in addition to those available in response to a needs' assessment and the teacher significantly adapts or designs tasks. Curriculum-development strategies, on the other hand, include experimentation, material writing and classification and involve both macro- and micro-level curriculum development (see also Shawer et al., 2009; Priestley et al., 2012). The micro-level strategies concern the use of textbooks and include using the textbook as a 'springboard of pedagogical content', being flexible about sequencing, and supplementing or adapting lesson content, and adapting or skipping textbook tasks (Shawer, 2010, p. 178). 
Arguably all three teacher-curriculum strategies could be evident in a classroom and there are many influences on the teacher-curriculum relationship where teachers 'evaluate, adopt, adapt and replace offerings of the curriculum' (Remillard, 2005, p. 234). Remillard in her work reminds us that the teacher-curriculum relationship is dynamic and tools both shape and are shaped by their affordances and constraints, and features of the curriculum matter as materials and teachers are players in an interactive relationship (Remillard, 2005; Remillard \& Heck, 2014; see also Pepin et al., 2013). The stage of curriculum making where the teacher uses their knowledge, experience and competences to shape the enacted curriculum is crucially important (Cohen \& Ball, 1999). The prevalence of a teaching culture in Irish mathematics classrooms that has a dependence on textbooks would point to a need for PSTs to engage with research on task classification and development if they are to develop curriculum making and development competences.

We situate task classification and development at the intersection between the selection of topics (curriculum scope) and organising pedagogical content (curriculum sequencing) and incorporating micro curriculum development strategies of textbook use (Shawer, 2010, p. 180). We propose that the frameworks used in this research, provide the conceptual tools to classify and design tasks, and that this is essential for the PSTs to engage in curriculum making in mathematics. We see task classification and task design as an essential skill that can be developed. We acknowledge that curriculum making is much more than task classification and design but argue that in mathematics where there is an over-reliance on textbooks it is one crucial area that impacts on teachers' ability to make curricular decisions as they implement the curriculum in their context-specific classrooms. In this context, the choice, design and adaptation of instructional materials is a key part of curriculum making (Remillard \& Heck, 2014). Figure 1 illustrates how task design and classification is linked to our theoretical framework.

In researching task classification and design with PSTs, we consider the curriculum materials available, and what the PSTs bring to the space in their own PCK, SMK and cultural scripts. We also are cognisant of what the research tells us that teachers need in order to adapt and design tasks, and we then look to the curriculum making strategies employed such as material evaluation strategies.

\section{Frameworks for classifying tasks}

A number of different frameworks have been developed to classify mathematical tasks and have proved useful in research, professional development and preservice teacher education (Boston \& Smith, 2011). In this research, we used three different but complementary frameworks with the participants. Two of the frameworks were concerned with classifying tasks. One looked at classifying tasks on the level of cognitive demand (Smith \& Stein, 1998) and the other on reasoning (Lithner, 2008). We discuss in detail only the Smith and Stein level of cognitive demand framework in this paper due to constraints on space.

The framework developed by Smith and Stein (1998) looks at the level of cognitive demand (LCD) of tasks. They identify two levels of cognitive demand: Lower-level 


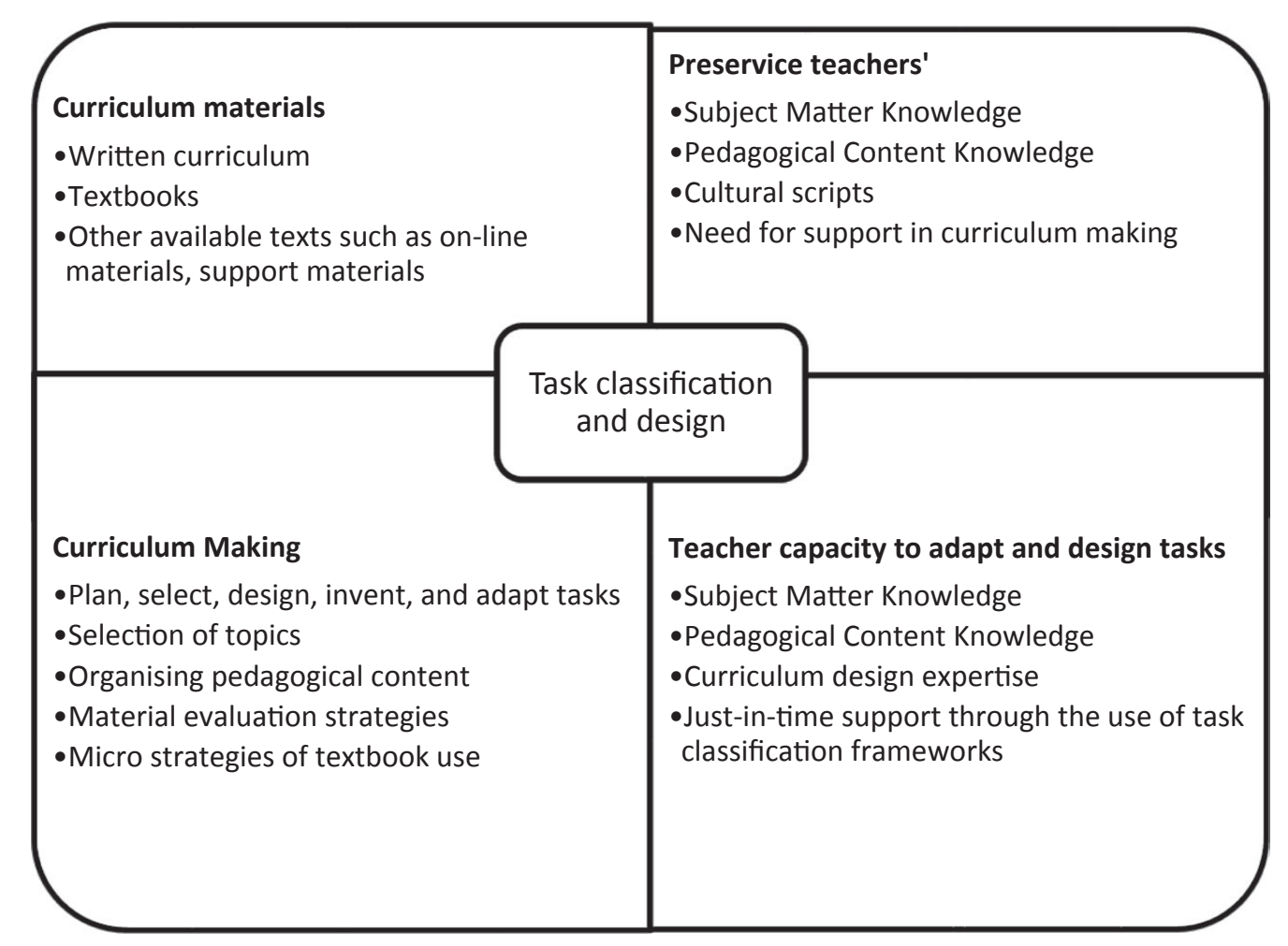

Figure 1. Task classification and design in curriculum making

demands (with task types of Memorisation, and Procedures without Connections to Meaning) and higher-level demands (Procedures with Connections to Meaning, and Doing Mathematics). The distinction between tasks is relevant, as the level of cognitive demand in a task provides different learning opportunities for the learner and demands a different learning environment for the development of competences required by the task. See Figure 2 for a full explication of this framework. The use of this framework can help alleviate some of the complexity involved in teachers' decision making about tasks and can enhance the user's ability to classify the task with reference to its application in the classroom (Jones \& Pepin, 2016).

Here we see how Smith and Stein provide explication for the classification of tasks. For example, to classify a task as Doing mathematics, the task must require students to explore and understand the nature of mathematical concepts, processes or relationships. If the task requires the student to use a procedure but does not require the student to make a connection to underlying concepts it is classified as Procedures without connection to meaning.

It is important to not just consider the tasks used during teaching but to also consider those used in homework activities and summative examinations. Homework that is focused on problem solving has a significant positive effect on students' mathematical achievement (Rosário et al., 2015); however, homework assignments that have the purpose of drill and practice are most often prescribed by teachers (Danielson et al., 2011). Therefore, we see the choice of tasks for homework assignments as another area of interest in looking at how mathematics teachers can engage in curriculum making. 


\begin{tabular}{|c|c|}
\hline Lower-level demands & Higher-level demands \\
\hline $\begin{array}{l}\text { Memorization: } \\
\text { - Involve either reproducing previously } \\
\text { learned facts, rules, formulas, or definitions or } \\
\text { committing facts, rules, formulas or } \\
\text { definitions to memory. } \\
\text { - Cannot be solved using procedures because a } \\
\text { procedure does not exist or because the time } \\
\text { frame in which the task is being completed is } \\
\text { too short to use a procedure. } \\
\text { - Are not ambiguous. Such tasks involve the } \\
\text { exact reproduction of previously seen material, } \\
\text { and what is to be reproduced is clearly and } \\
\text { directly stated. } \\
\text { - Have no connection to the concepts or } \\
\text { meaning that underlie the facts, rules, } \\
\text { formulas, or definitions being learned or } \\
\text { reproduced. }\end{array}$ & $\begin{array}{l}\text { Procedures with Connections to Meaning: } \\
\text { - Focus students' attention on the use of } \\
\text { procedures for the purpose of developing } \\
\text { deeper levels of understanding of } \\
\text { mathematical concepts and ideas. } \\
\text { - Suggest explicitly or implicitly pathways to } \\
\text { follow that are broad general procedures that } \\
\text { have close connections to underlying } \\
\text { conceptual ideas as opposed to narrow } \\
\text { algorithms that are opaque with respect to } \\
\text { underlying concepts. } \\
\text { - Usually are represented in multiple ways, } \\
\text { such as visual diagrams, manipulatives, } \\
\text { symbols, and problem situations. Making } \\
\text { connections among multiple representations } \\
\text { helps develop meaning. } \\
\text { - Require some degree of cognitive effort. }\end{array}$ \\
\hline $\begin{array}{l}\text { Procedures without Connection to Meaning: } \\
\text { - Are algorithmic. Use of the procedure either } \\
\text { is specifically called for or is evident from } \\
\text { prior instruction, experience, or placement of } \\
\text { the task. } \\
\text { - Require limited cognitive demand for } \\
\text { successful completion. Little ambiguity exists } \\
\text { about what needs to be done and how to do it. } \\
\text { - Have no connection to the concepts or } \\
\text { meaning that underlie the procedure being } \\
\text { used. } \\
\text { - Are focused on producing correct answers } \\
\text { instead of on developing mathematical } \\
\text { understanding. } \\
\text { - Require no explanations or explanations that } \\
\text { focus solely on describing the procedure that } \\
\text { was used. }\end{array}$ & $\begin{array}{l}\text { Doing Mathematics: } \\
\text { - Require complex and nonalgorithmic } \\
\text { thinking-a predictable, well-rehearsed } \\
\text { approach or pathway is not explicitly } \\
\text { suggested by the task, task instructions, or a } \\
\text { worked-out example. } \\
\text { - Require students to explore and understand } \\
\text { the nature of mathematical concepts, } \\
\text { processes, or relationships. } \\
\text { - Demand self-monitoring or self-regulation of } \\
\text { one's own cognitive processes. } \\
\text { - Require students to access relevant } \\
\text { knowledge and experiences and make } \\
\text { appropriate use of them in working through } \\
\text { the task. } \\
\text { - Require students to analyze the task and } \\
\text { actively examine task constraints that may } \\
\text { limit possible solution strategies and solutions. } \\
\text { - Require considerable cognitive effort and } \\
\text { may involve some level of anxiety for the } \\
\text { student because of the unpredictable nature of } \\
\text { the solution process required. }\end{array}$ \\
\hline
\end{tabular}

Figure 2. Smith and Stein levels of demand. Source: Smith and Stein (1998)

\section{Framework for developing tasks}

Studies have previously looked at the issue of task classification and development as part of professional development courses for in-service teachers. For example, Boston and Smith (2011) describe a task-centric approach to such courses where the focus is on teachers' ability to select and implement cognitively demanding tasks. Arbaugh and Brown (2005) used a similar approach and found that introducing teachers to criteria for high-level tasks influenced their task selection and ultimately their pedagogical content knowledge (PCK).

In order to help the PSTs to move from classifying tasks to designing them, we explored the creation of tasks using Swan's Framework for task design. Swan's framework (2008) describes five task types that encourage concept development and provides very clear design principles to inform task development and implementation. 
The five task types that he posits will encourage concept development are: classifying mathematical objects, interpreting multiple representations, evaluating mathematical statements, creating problems, and, analysing reasoning and solutions. There are many examples of Swan's mathematics tasks available on-line, see for example http:// map.mathshell.org/background.php Task design is a complex process and involves cycles of design before, during and after the teaching event (Remillard, 2005; Pepin et al., 2013; Huizinga et al., 2014). The design process involves specific curriculum design expertise with two types of knowledge and skills relevant to this research project, Subject Matter Knowledge (SMK) and Pedagogical Content Knowledge (PCK) (Ball et al., 2008). SMK is important in the classification and design of tasks as PSTs need to know their subject in order to make curriculum material evaluations and they need to use PCK in order to make decisions with respect to the specific context in which they will implement the task (Remillard, 2005; Remillard \& Heck, 2014).

\section{Methodology}

\section{Design of the study}

All 19 preservice teachers in the second semester of year three of a five-year postprimary teacher education course took part in the research project. Research purpose and relevance were discussed with the PSTs; ethical approval was sought and granted. At the time of the research the PSTs were midway through their second school placement experience and were teaching a minimum of two hours per week. Participants were taking mathematics in their degree and one other science subject (either biology, chemistry or physics). The research is presented as a case study using mixed data collection methods looking at the group of PSTs as a whole, over a sustained period of time as they developed competences in task design (Yin, 2018). This allowed us to build on earlier research (Boston, 2013) and incorporate PSTs reflections on the design process.

An interdisciplinary team, one Education and one Mathematics specialist designed the workshops that form the core of this research. Prior to this project, the mathematics and education modules studied by students on the programme were not integrated. The PSTs took a methodology course in Mathematics Education that did not have a focus on task classification and development; rather it was focused on curriculum topics and pedagogical strategies. This is not unusual in Ireland and is similar to the situation described by Masingila et al. (2012).

The instructional workshops had the following key characteristics where the PSTs used and applied the frameworks to examples from the textbooks they used in teaching and to State Examination Commission (SEC) materials in collaborative working groups (Brown, 2009; Jones \& Pepin, 2016). The aim was to give them opportunities to develop skills in the classification and selection of tasks. The workshops were interactive and activity-based, encouraging participants to develop their own thinking on task classification and development, in order to promote individual and collective professional development in real situations (Stylianides \& Stylianides, 2010). The PSTs were supported while they worked on the design and adaptation of tasks using 
the Swan (2008) framework. Content and pedagogical activities were organised into sequences that engaged participants across the continuum from learner to teacher (Steele \& Hillen, 2012). They engaged in 'sense-making activities' while working together on tasks (Thanheiser, 2014, p. 168). The primary aim of the content and pedagogical material was to develop the PSTs' understanding of mathematical concepts (SMK) and also to link their mathematical understanding and task classification and design skills to develop PCK.

Data collection and analysis. Jones and Pepin (2016) contend that when teachers interact with mathematical tasks, they develop knowledge; this is done individually in preparing and planning for teaching and collectively when they are afforded opportunities to develop and discuss tasks with peers. In designing curriculum materials, PSTs need both subject matter knowledge (SMK) and pedagogical content knowledge (PCK) (Ball et al., 2008; Huizinga et al., 2014). In order to investigate any gain in knowledge about the classification of the cognitive demand of tasks for the group over the course of the intervention, we administered a pre and a posttest designed by Boston (2013). This test asked students to classify 16 tasks as either high-level or low-level tasks, and to give a rationale for their choice. At the end of the module, the preservice teachers were asked to complete an evaluation questionnaire that asked them: to report on a key learning moment during the module; whether their teaching had changed as a result of the module and if so, in what way. Thirteen of the 19 students submitted the evaluation questionnaire.

The assessment for the module consisted of the assignment, which asked the following questions,

For a topic of your choice design (or significantly adapt) a series of tasks. One task/s should be suitable to be used in class while teaching, and, one for use as homework. Design an examination task/s for the topic. Present your rationale for each task based on your readings.

Reflect on the differences between classroom task, homework task and examination tasks.

All 19 preservice teachers submitted this assignment and gave their consent to use it for research purposes. The tasks designed by the PSTs were analysed using the LCD and Lithner Frameworks. The classification was conducted by two researchers who were familiar with the curriculum, assessment and textbooks relevant to the classes taught by the PSTs. The researchers used their knowledge to decide if (in the context of the PSTs' classes) the tasks should be classified as either high- or low-level tasks. Evidence that PSTs employed aspects of Swan's (2008) framework in their design was noted.

In year five of the course, two years after the PSTs had taken the module, a sample $(n=5)$ took part in an interview. Data from the qualitative analysis of the interviews are presented in this paper. During the interview, the PSTs were asked to indicate their levels of agreement with 46 statements (28 on teaching practices which were taken from Swan and Swain (2010), and the remainder on their experiences of the classification and design of tasks). The interviewer asked the teachers to explain their ranking of these statements, and in this way sought to get information about the PSTs view of teaching and task design. The interviews were recorded and transcribed. A 
general deductive approach was taken to analyse the students' reflections on the differences between types of tasks. Analysis was guided by the research questions and a number of a priori themes (such as Subject Matter Knowledge (SMK) and Pedagogical Content Knowledge (PCK); Ball et al., 2008), and allowed flexibility for other themes to emerge. The analysis followed the five procedural steps outlined by (Thomas, 2006), namely: preparation of raw data files, close reading of text, creation of categories, overlapping coding and uncoded text, and continuing revision and refinement of the category system. The coding process used to identify the categories (themes) involved labelling categories, writing descriptions of the labelled categories, and identifying PST responses that relate to the specific categories to exemplify the meaning of the category. The first step involved the independent identification of themes and coding of raw data by the two researchers, then a discussion of how the themes linked to the research questions and the concepts identified in the literature. Independent coding and comparison with previous research were the primary considerations employed to ensure the trustworthiness of data in the study. Quotes used in this paper represent the examples of common responses in categories.

\section{Findings}

The findings reported seek to answer the following three research questions:

1. In what ways did preservice teachers' ability to classify the cognitive demands of mathematical tasks develop during their participation in a module on critical classification and design of mathematical tasks?

2. In what ways did preservice teachers' ability to design or adapt mathematical tasks develop during their participation in a module on critical classification and design of mathematical tasks?

3. How did the development of these abilities impact on how PSTs used tasks in curriculum development and making?

PSTs' specific learning about the classification of cognitive demand. We will first consider the data from Boston's pre and posttests on the classification of the level of tasks. The PSTs' scores on the pre-test ranged from 14 to 31 with a mean of 21.67 and a standard deviation of 5.224 (maximum possible score was 36). On the posttest the scores ranged from 16 to 32 with a mean of 22.93 and a standard deviation of 4.548 . Since 13 participants completed both tests, we used a paired $t$-test to investigate whether the mean of the group had increased significantly from the pre to the posttest. The differences between pre and posttest scores were computed for each of the 13 preservice teachers and this variable was tested for normality using the Shapiro-Wilk test. We concluded that the differences were normally distributed $(p=0.58)$ and so the paired t-test was performed. This indicated a significant increase from the pre to the posttest mean scores $(p=0.037)$. Since the number of pairs is low, we also carried out a non-parametric test namely the Wilcoxon Signed Rank test. We found evidence $(p=0.045)$ that the median difference in test scores is not zero; there is a significant difference in the pre and posttest scores. (We note that the p-value here 
is marginal, which may be a consequence of the small number of pairs in our study.) We conclude that there is evidence that the PSTs have developed an enhanced ability to classify the cognitive demand of tasks over the course of the intervention.

There was also evidence for PSTs developing an appreciation for the importance of the level of cognitive demand in tasks in their response to the question on the end of module evaluation, which asked for their key learning moment.

Realising the different reasoning and thinking about the type of question. In the textbook, where homework is usually given from, questions are repeated, low demand. In the maths exam students are faced with high-level conceptual questions so there is a big gap there that needs to be addressed.

(S14, reflection)

Here we see that S14 is noticing the level of demand and reasoning in the artefacts available to them in their teaching, the textbook. The recognition of this by the PSTs was notable in many comments such as, now, having seen the different levels, I generally spend more time selecting and developing questions (S16, reflection).

Development of the ability to adapt and design tasks. The analysis of the PSTs' end of module assignments gave evidence of them developing the ability to enhance and design tasks. All students showed that they were able to design or modify tasks to get high-level cognitive demand questions. The PSTs classification of their tasks using the LCD and reasoning frameworks further demonstrated that they were competent in using the frameworks for classification. This evidenced a growth in Subject Matter Knowledge SMK (in classifying tasks) and Pedagogical Content Knowledge PCK (in how they thought about and choose tasks) (Ball et al., 2008; Huizinga et al., 2014).

The types of tasks designed seemed to fall into two broad camps: open-ended exploratory tasks (which were mainly found in the classroom setting) and more traditional formats (which were mainly found in homework and examination tasks). The latter types of tasks mostly consisted of word problems with a real-life context; the PSTs designed a small number of other types of tasks for use as homework or examination questions, including tasks, which required students to make a conjecture, provide an example, or evaluate a mathematical statement. In addition, one PST designed a homework task, which involved a preclass investigation. The majority (13 of 19) of the PSTs used card-matching designs for their classroom tasks. These tasks were based on Swan's 'Interpreting Multiple Representations' (Swan, 2008, p. 3) task type. The PSTs were introduced to this idea through the Swan (2008) article and also participated in a card-matching task (on the topic of fractions) during one of the module sessions. Three of the PSTs used games (such as 'Battleships' and dice games) to devise tasks for use in the classroom, two PSTs used investigations as the basis of their task and one designed a series of worksheets with problems of increasing difficulty.

The PSTs showed creativity and an appreciation for tasks with high levels of cognitive demand. However, an analysis of their designed tasks showed that the design process was not without difficulty for the group. Some of the questions were not always clear due to missing or confusing instructions, and sometimes the context made the 
question ambiguous (this has also been a problem in state examinations in Ireland). Occasionally it seemed as if the PSTs did not have a clear understanding of the underlying mathematics themselves, possibly owing to their level of Subject Matter Knowledge (SMK), and sometimes their use of mathematical language caused difficulty (such as using the term 'equation' instead of 'expression' for something like $2 x+1)$. Huizinga et al. (2014) cite the importance of SMK and research by Steel and colleagues highlight the need to provide content-focused methods courses (Steele \& Hillen, 2012; Steele et al., 2013). The learning trajectories for the tasks or sets of tasks were not always clear-sometimes it was not clear what understanding and what concept the PSTs were trying to develop. This links in with curriculum-making strategies needed for developing a curriculum sequence (Shawer, 2010).

Impact on preservice teachers' pedagogical content knowledge and the move to curriculum making. The PSTs' knowledge of levels of cognitive demands challenged their deeply held view of how best to teach mathematics. Previous research with PSTs found that they focused on the content when planning for teaching and placed little emphasis on the learner or prior learning (Nolan et al., 2015). At the end of the module survey, all 13 of the respondents said that the module impacted on how they taught mathematics with all but one cited a change in how they asked questions and placed more emphasis on higher level of cognitive demand in questions. Prior to this module, these PSTs had completed a module that included a significant input on questioning skills for teaching; however, they appeared to have needed the familiarity with the task classification frameworks in order to have changed their questioning practices. It must be noted that this was self-reported, but an increased emphasis on discussing mathematics problems appears to be evident with comments such as

I try to think more about pushing my students to reason more when completing tasks. I try to ask questions, give tasks to my students much less information, and I want my students to rely less on me giving them the answer.

(S11, reflection)

This PST also spoke about the effect of the intervention on her teaching:

I never really thought much into the differences between the tasks that I give during class, homework or exams or the impact it could have on my students' development in a subject. Having studied and researched the classification of math's tasks and implementing my own selection/adaption of tasks into my class, I now feel that I have gained a deeper understanding into the effect my choice of tasks can have on progression and learning....

(S11, reflection)

Two years later all five interviewees cited the similar changes with quotes such as:

They (frameworks) just made you to think about ... where you were coming from with your questions. ... Before participating in ED310 (the module code) I wouldn't really have thought about where your questions were actually coming from.

(S4, interview, year 5)

Before I did that module, I wouldn't have thought about homework tasks as much as I do now. Now I make sure I develop a good homework task. Like there's no point in giving homework for the sake of giving homework. If I haven't got a good homework task there's no point in saying, oh do questions 1-10.

(S1, interview, year 5) 
The PSTs spoke of how the practice of thinking about levels of cognitive demand was embedded into their planning now. They all critiqued aspects of the use of end of chapter questions and linked the need for good tasks to achievement and to student interest in mathematics. This awareness of the importance of tasks and the importance of teachers critically evaluating tasks may indicate to a move to curriculum making. The PSTs who implemented their tasks in their teaching placements, realised the effect that the teacher can have on the cognitive level of the task and this led to them thinking about different types of tasks or redesigning their original tasks:

The students struggled very much with it at the beginning and due to my own fault I went through an algorithm with them and then the task immediately became a lower demand one, just requiring the students to reproduce an algorithm each time. If I were to redesign the tasks, I would change tasks $E$ and $F$ [card-matching tasks] to tasks where the students have to spot a mistake in a question/statement and justify their reasoning and how they would alter the question/statement ... in order to encourage them to develop critical thinking skills.

(S12, reflection)

This reflection would suggest that the PST is developing her thinking on organising pedagogical content, adapting materials to suit students and adopting curriculum planning and making strategies, the teacher-curriculum relationship is more evident in her reflection (Remillard, 2005; Shawer, 2010).

When interviewed 2 years later there was evidence that the process of classifying and designing tasks continues to impact their teaching. They mentioned using the frameworks on a day-to-day basis, the importance of designing or modifying tasks for specific groups, the importance of high level and novel tasks, and the problem of repetitive tasks in textbooks. They mentioned that now that they have more control over their teaching (in year five of the course PSTs teach for three days in their schools), they have been able to incorporate more of their own tasks in their teaching.

If you are trying to bring your students on and bring learning forward, you need to be developing
tasks... Once you get used to developing the tasks in that way you are not going to forget how to
use them [the framezorks]. I use them all the time.You are kind of using it and you forget you are
using it.
(S1, interview, year 5)

And I look at different textbooks, and then I might modify the difficulty of them. The student might have the same question, but it's asked in a different way. It's hitting different levels of cognitive demand.

(S5, interview, year 5)

We see here that the PSTs are thinking about the role of homework and how the type of task used is an important consideration. We see also a move from an over-reliance on the textbook and the willingness to design and adapt tasks; this would indicate a move to curriculum making. There is evidence of having incorporated the task classification into their practice.

\section{Limitations of the study}

We note that much of the evidence we have provided in this article is based on selfreported data and not on classroom observations. While this research project has been very insightful for all involved it is important to note that the cognitive demand of any task can be lowered in practice by the way in which it is implemented. If the 
teacher scaffolds the problem so that the student is led in an algorithmic way through it, then the task is probably not going to be as demanding for them (Sears \& Chávez, 2014; Smith \& Stein, 1998). Observing task enactment in the classroom would have enabled us to make a stronger link for task classification and development to curriculum making with PSTs' practice. However, we are heartened by the move to thinking about task enactment in the interviews 2 years after the module was completed.

\section{Discussion}

Our review of the literature in this area has highlighted the central roles that task selection and design play in the teaching of mathematics (Bergqvist \& Lithner, 2012; Sears \& Chávez, 2014) and in the process of mathematics curriculum development (Shawer, 2010; Remillard \& Heck, 2014). Our analysis has shown that the PSTs in this study have been able to work in what Remillard $(1999,2005)$ described as the design arena. We acknowledge that what we have presented evidence for here is the ability to select and enrich tasks rather than design capacity which would include, for example, the design of learning trajectories (See e.g. Pepin et al., 2017). We have seen that increasing the PSTs awareness of different levels of tasks and giving them an opportunity to design and modify tasks has helped them to develop skills such as the ability to classify tasks and design tasks at different levels. They also seem to have developed knowledge especially PCK which linked to their ability to classify levels of cognitive demand has enabled them to adapt their practice, especially around questioning. This leads us to posit that the PSTs have also begun to operate in the construction arena (Remillard, 1999, 2005). We saw that the participants reported using many of the micro-strategies of curriculum development (Shawer, 2010) such as an increased flexibility and willingness to omit or adapt textbook tasks and to design original ones.

The importance of applying frameworks in order to increase awareness of concepts such as levels of cognitive demand is significant for PST education; awareness may be a crucial first step in knowledge acquisition. PSTs come to teaching with very strong cultural scripts and pedagogical beliefs that tend to be more traditional than progressive (Conway et al., 2011), the use of the frameworks for design and classification of tasks has encouraged them to question their curriculum choices and this move has persisted in the PSTs' practice. When interviewed after 2 years there was some evidence of having changed beliefs (about the types of tasks to use) and practice (not being over-reliant on the textbook), and of the PSTs engaging in reflection on their everyday work as mathematics teachers. Similar to findings from Boston (2013) and Swan (2007) who worked with practicing teachers, our research appears to demonstrate the need for an awareness of cognitive demand in order for mathematics educators to be able to select and develop rich and engaging tasks. This increase in knowledge and skills seems to be crucial in order to make the transition from curriculum transmitters to curriculum makers (Shawer, 2010). The space in our intervention for discussing textbook questions and State Examinations Commission materials was cited as being the most impactful for the PSTs. The process of enactment in the workshops, how the PSTs work with the resources and develop resources 
requires further more in-depth research to move it beyond the descriptive level. The need for space for curriculum making and professional learning, and, the challenges therein has not been fully explored within PST education before now.

The Smith and Stein Framework proved to be accessible for the PSTs and the use of it persisted over time from 3 to 5 years. We believe that this is because of the opportunities provided for on-going construction out of enacted experience as they worked with peers and with their students. Here we see these frameworks as curriculum making artefacts that enable the PSTs to build confidence and competences in task classification and design and aid in their planning for teaching. Our PSTs moved to look at task development in other subject areas, they adapted the curriculum resource to suit their context; their planning for teaching appeared to become more task-centric.

This brings us to think about how we worked with the PSTs. In their evaluations, they cited being able to work collaboratively on tasks was significant for them. PSTs talked about the need for more time to interact with tasks, especially tasks developed by peers. They wanted more discussion time on tasks. The necessity for deliberate practice and time for discussion and reflective analysis in task development and implementation have been identified by a number of recent studies (Arbaugh $\&$ Brown, 2005; Furtak et al., 2016; Stürmer et al., 2016). On reflection and having worked on this module now for 4 years, we feel the space for discussing different tasks and applying the frameworks is significant and would concur with other research on professional learning (Jones \& Pepin, 2016).

This research has highlighted a gap in the PSTs' education on task design in the case study institution, and, as such was used to make changes to the module design and implementation. The focus on tasks moved to PSTs considering enactment in their classrooms. This was especially evident when the participants had more input into their teaching in year five and so we see that the use of frameworks to scaffold PSTs' thinking around the cognitive demand of tasks was successful and persisted over time.

We acknowledge that task classification is only part of curriculum making, however we see it as a crucial first step for the novice teacher. Indeed, the PSTs and new teachers may not have many opportunities to display independence within the constraints of the Irish Education system, and may not even be able to choose the particular textbook to use with their classes. They do have the freedom to make choices about the tasks that they use, and this is an area where they can design and plan learning experiences for their students to help develop the mathematical understanding (Remillard \& Heck, 2014). Task classification and design are curriculum making activities for mathematics teachers and our data show that the development of skills in these areas can have lasting effects on PSTs' practices and willingness to engage meaningfully with the curriculum. We have seen that in designing tasks, PSTs can make the first steps towards becoming curriculum developers.

\section{Funding}

This research received the Maynooth University Fellowship funding. 


\section{Disclosure statement}

There are no potential conflicts of interest.

\section{Geolocation information}

Maynooth University, Ireland W23F2H6.

\section{Data availability statement}

The data are not available.

\section{NOTE}

${ }^{1}$ The Project Maths initative was introduced in 24 phase one schools in September 2008 and rolled out to all post-primary schools in September 2010.

\section{References}

Arbaugh, F. \& Brown, C. A. (2005) Analysing mathematical tasks: A catalyst for change? fournal of Mathematics Teacher Education, 8(6), 499-536.

Ball, D. L., Thames, M. H. \& Phelps, G. (2008) Content knowledge for teaching: What makes it special? Fournal of Teacher Education, 59(5), 389-407.

Banks, J. \& Smyth, E. (2015) 'Your whole life depends on it': Academic stress and high-stakes testing in Ireland, Fournal of Youth Studies, 18(5), 598-616.

Bergqvist, T. \& Lithner, J. (2012) Mathematical reasoning in teachers' presentations, fournal of Mathematical Behavior, 31(2), 252-269.

Boston, M. (2013) Connecting changes in secondary mathematics teachers' knowledge to their experiences in a professional development workshop, fournal of Mathematics Teacher Education, $16(1), 7-31$.

Boston, M. D. \& Smith, M. S. (2009) Transforming secondary mathematics teaching: Increasing the cognitive demands of instructional tasks used in teachers' classrooms, fournal for Research in Mathematics Education, 40(2), 119-156.

Boston, M. \& Smith, M. S. (2011) A 'task-centric approach' to professional development: enhancing and sustaining mathematics teachers' ability to implement cognitively challenging mathematical tasks, ZDM, 43(6-7), 965-977.

Brown, M. (2009) The teacher-tool relationship: Theorizing the design and use of curriculum materials, in: J. T. Remillard, B. Herbel-Eisenmann \& G. Lloyd (Eds) Mathematics teachers at work: Connecting curriculum materials and classroom instruction (New York, NY, Routledge), $17-36$.

Cohen, D. K. \& Ball, D. L. (1999) Instruction, capacity, and improvement. CPRE Research Report Series RR-43 (Philadelphia, PA: Consortium for Policy Research in Education, University of Pennsylvania).

Conway, P. \& Sloane, F. (2005) International trends in post-primary mathematics education: Perspectives on learning, teaching and assessment (Dublin, NCCA).

Conway, P., Murphy, R., Delargey, M., Hall, K., Kitching, K., Long, F., et al. (2011) Learning to teach (LETS): Developing curricular and cross curricular competences in becoming a 'good'secondary teacher: Executive summary (Cork, School of Education, University College Cork).

Conway, P., Murphy, R. \& Rutherford, V. (2013) Re-imagining initial teacher identity and learning study: Final report (Cork, School of Education, University College Cork (UCC)).

Danielson, M. L., Strom, B. \& Kramer, K. (2011) Real homework tasks: A pilot study of types, values, and resource requirement, Educational Research Quarterly, 35(1), 17-32. 
Flores, M. A. \& Day, C. (2006) Contexts which shape and reshape new teachers' identities: A multi-perspective study, Teaching and Teacher Education, 22, 219-232.

Furtak, E. M., Kiemer, K., Circi, R., Swanson, R., DeLeon, V., Morrison, D., et al. (2016) Teachers' formative assessment abilities and their relationship to student learning: Findings from a four-year intervention study, Instructional Science, 44, 267-291.

Haggarty, L. \& Pepin, B. (2002) An investigation of mathematics textbooks and their use in English, French and German classrooms: Who gets an opportunity to learn what? British Educational Research fournal, 28(4), 567-590.

Huizinga, T., Handelzalts, A., Nieveen, N. \& Voogt, J. M. (2014) Teacher involvement in curriculum design: Need for support to enhance teachers' design expertise, fournal of Curriculum Studies, 46(1), 33-57.

Jeffes, J., Jones, E., Wilson, M., Lamont, E., Straw, S., Wheater, R., et al. (2013) Research into the impact of project maths on student achievement, learning and motivation: Final report (Slough, NFER).

Jones, K. \& Pepin, B. (2016) Research on mathematics teachers as partners in task design, fournal of Mathematics Teacher Education, 19(2-3), 105-121.

Jonsson, B., Norqvist, M., Liljekvist, Y. \& Lithner, J. (2014) Learning mathematics through algorithmic and creative reasoning, The fournal of Mathematical Behaviour, 36, 20-32.

Lithner, J. (2008) A research framework for creative and imitative reasoning, Educational Studies in Mathematics, 67, 255-276.

Lithner, J. (2017) Principles for designing mathematical tasks that enhance imitative and creative reasoning, ZDM-The International fournal on Mathematics Education, 49(6), 937-949.

Masingila, J. O., Olanoff, D. E. \& Kwaka, D. K. (2012) Who teaches mathematics content courses for prospective elementary teachers in the United States? fournal of Mathematics Teacher Education, 15, 347-358.

National Council for Curriculum and Assessment (2008). Mathematics Syllabus. (Dublin: The Stationary Office). Available online at: www.ncca.ie

Nolan, B., Dempsey, M., Lovatt, J. \& O'Shea, A. (2015) Developing Mathematical Knowledge for Teaching (MKT) for preservice teachers: A study of students' developing thinking in relation to the teaching of mathematics, Proceedings of the British Society for Research into Learning Mathematics, 35(1), 54-59.

O'Keeffe, L. \& O'Donoghue, J. (2011) A review of school textbooks for project maths (Limerick, NCE-MSTL).

Olson, M. (2000) Curriculum as a multistoried process, Canadian fournal of Education, 25(3), $169-187$.

Pepin, B., Gueudet, G. \& Trouche, L. (2013) Re-sourcing teachers' work and interactions: a collective perspective on resources, their use and transformation, ZDM, 45, 929-943.

Pepin, B., Gueudet, G. \& Trouche, L. (2017) Refining teacher design capacity: Mathematics teachers' interactions with digital curriculum resources, ZDM Mathematics Education, 49(5), 799-812.

Priestley, M. \& Philippou, S. (2018) Curriculum making as social practice: Complex webs of enactment (Editorial), Curriculum fournal, 29(2), 151-158.

Priestley, M., Edwards, R., Priestley, A. \& Miller, K. (2012) Teacher agency in curriculum making: Agents of change and spaces for Manoeuvre, Curriculum Inquiry, 42(2), 191-214.

Remillard, J. T. (1999) Curriculum materials in mathematics education reform: A framework for examining teachers' curriculum development, Curriculum Inquiry, 29(3), 315-342.

Remillard, J. T. (2005) Examining key concepts in research on teachers' use of mathematics curricula, Review of Educational Research, 75(2), 211-246.

Remillard, J. T. \& Heck, D. J. (2014) Conceptualizing the curriculum enactment process in mathematics education, ZDM The International fournal on Mathematics Education, 46(5), 705-718.

Rosário, P., Núñez, J. C., Vallejo, G., Cunha, J., Nunes, T., Mourão, R., et al. (2015) Does homework design matter? The role of homework's purpose in student mathematics achievement, Contemporary Educational Psychology, 43, 10-24. 
Sears, R. \& Chávez, Ó. (2014) Opportunities to engage with proof: The nature of proof tasks in two geometry textbooks and its influence on enacted lessons, ZDM The International fournal on Mathematics Education, 46(5), 767-780.

Shawer, S. F. (2010) Classroom-level curriculum development: EFL teachers as curriculumdevelopers, curriculum makers and curriculum-transmitters, Teaching and Teacher Education, 26, 173-184.

Shawer, S., Gilmore, D. \& Banks-Joseph, S. R. (2009) Learner-driven EFL curriculum development at the classroom level, International fournal of Teaching and Learning in Higher Education, 20(2), 125-143.

Smith, M. S. \& Stein, M. K. (1998) Selecting and creating mathematical tasks: From research to practice, Mathematics Teaching in the Middle School, 3, 344-350.

Snyder, J., Bolin, F. \& Zumwalt, K. (1992) Curriculum implementation, in: P. W. Jackson (Ed) Handbook of research on curriculum (New York, NY, Macmillan), 402-435.

Steele, M. D. \& Hillen, A. F. (2012) Content-focused methods courses: Integrating pedagogy and mathematical content that is central to the 7-12 curriculum, Mathematics Teacher Educator, 1, 52-69.

Steele, M. D., Hillen, A. F. \& Smith, M. S. (2013) Developing mathematical knowledge for teaching in a methods course: the case of function, fournal of Mathematics Teacher Education, 16(6), 451-482.

Stein, M. K., Grover, B. W. \& Henningsen, M. (1996) Building student capacity for mathematical thinking and reasoning: An analysis of mathematical tasks used in reform classrooms, American Educational Research fournal, 33, 455-488.

Stürmer, K., Seidel, T. \& Holzberger, D. (2016) Intra-individual differences in developing professional vision - preservice teachers' changes in the course of an innovative teacher education program, Instructional Science, 40, 293-209.

Stylianides, A. J. \& Stylianides, G. J. (2010) Mathematics for teaching: A form of applied mathematics, Teaching and Teacher Education, 26, 161-172.

Swan, M. (2007) The impact of task-based professional development on teachers' practices and beliefs: A design research study, fournal of Mathematics Teacher Education, 10, 217-237.

Swan, M. (2008) Designing a multiple representation learning experience in secondary algebra, Educational Designer, 1(1), 1-17.

Swan, M. (2011) Designing tasks that challenge values, beliefs and practices: A model for the professional development of practicing teachers, in: O. Zaslavsky \& P. Sullivan (Eds) Constructing knowledge for teaching secondary mathematics (New York, NY, Springer).

Thanheiser, E. (2014) Developing prospective teachers' conceptions with well-designed tasks: Explaining successes and analyzing conceptual difficulties, fournal of Mathematics Teacher Education, 18(2), 141-172.

Thomas, D. R. (2006) A general inductive approach for analyzing qualitative evaluation data, American fournal of Evaluation, 27(2), 237-246.

Wallace, C. \& Priestley, M. (2017) Secondary science teachers as curriculum makers: Mapping and designing Scotland's new curriculum for excellence, Fournal of Research in Science Teaching, 54(3), 324-349.

Yin, R. K. (2018) Case study research and applications: Design and methods (6th edn) (Thousand Oaks, CA, Sage). 